\title{
Magnitude and Factors Associated with Khat Chewing among Undergraduate Students of Adama University, Oromia National Regional State, January 2012
}

\author{
Getu Teshome \\ Public Health Department, Arsi University, Assela, Oromia, Ethiopia \\ Email: g teshome86@yahoo.com
}

Received 24 December 2014; accepted 10 January 2015; published 15 January 2015

Copyright (C) 2015 by author and OALib.

This work is licensed under the Creative Commons Attribution International License (CC BY). http://creativecommons.org/licenses/by/4.0/

c) (i) Open Access

\section{Abstract}

Background: In some countries the use of Khat is widespread. The use or misuse of Khat is increasingly prevalent in Ethiopia. College and university students consume Khat to get mental alertness and to work hard in their academic endeavours. Most of the studies concerning Khat chewing were done on community-based studies and high school-based as well as psychiatric effects of Khat: less was done among university students. Objective: The study was aimed to assess the prevalence and associated factors of Khat chewing among undergraduate Adama University students. Methodology: A cross-sectional study using self-administered questionnaire was conducted on population sample size determined by using single population proportion formula in January 2012. By using multi-stage sampling technique followed by simple random sampling, one department was selected from each school. Then, by simple random sampling, the sampled students were selected proportionally to their year of study and class size. Questions regarding demographic variables, academic and environmental factors were included in the survey. Data quality was controlled by pre-test, supervision, translation and training data collectors. Completed data were coded and entering into EPI info version 3.5.1 and analyzed by SPSS version 16. Odds ratio with $\mathbf{9 5 \%}$ CI and multiple logistic regression analysis were used. Results: A total of 728 students participated giving a response rate of $95.3 \%$. The lifetime and current prevalence of Khat chewing were found to be $27.7 \%$ and $20.7 \%$ respectively. Being male $(A O R=1.95 ; 95 \%$ CI 1.10 3.47), monthly pocket money $(\mathrm{AOR}=1.52 ; 95 \% \mathrm{CI}=1.01-2.28)$, family history of Khat chewing $(A O R=1.72 ; 95 \% C I=1.14-2.59)$ and friend chewing $K h a t(A O R=1.70 ; 95 \% \mathrm{CI}=1.12-2.58)$ were associated factors for Khat chewing $(p<0.05)$. Conclusion and Recommendation: The prevalence of Khat chewing among Adama University students was high compared to other studies done in similar settings. Therefore, there is a need for early intervention that targets university students to reduce impact of peer pressure, family history of Khat chewing and proper management of money. To realize this involvement and participation of policy makers, ministry of education, universities and parents are mandatory. 


\title{
Keywords
}

\section{Khat Chewing, Magnitude, Students, Adama University}

\author{
Subject Areas: Epidemiology, Public Health
}

\section{Background}

In some countries where the use of Khat (Catha edulis Forsk) is widespread, the habit has a deep-rooted social and cultural tradition. This is particularly true for Ethiopia [1]. Several million people may be chewing Khat worldwide, with an estimated 10 million people chewing Khat leaf daily [2]. It is an evergreen plant that grows mainly in Ethiopia, Yemen and other African countries along the coast of the Indian Ocean favouring altitudes of between 5000 and 6500 feet above sea level, a good altitude for coffee and tea production [3]. Fresh leaves and buds of the Khat plant contain cathinone, an amphetamine like alkaloid responsible for its pharmacological action [4].

College and university students consume Khat to get mental alertness and to work hard in their academic endeavours [5]. Traditionally, it is commonly used for prayer and during Moslem fasting seasons [6] [7]. However, nowadays, many Christians especially the young also use it [5]. Alcohol and Khat were the two "drugs" commonly ever tried by high school students both in government and private schools [8].

Insomnia is a common problem associated with the use of Khat which prompts the chewer to use/misuse sedatives and to indulge in alcohol as a means of overcoming the side effect [8] [9].

In Ethiopia, the use or misuse of addictive substances, such as cigarettes, alcohol, and Khat (Catha edulis Forsk) is increasingly prevalent in Ethiopia [10] [11]. However, most of the studies were done at community and high school level. Therefore, this study was intended to study the prevalence and associated factors of Khat chewing among undergraduate students of Adama University.

Khat (Catha edulis Forsk) is a natural stimulant from the Catha edulis plant, found in the flowering evergreen tree or large shrub of Celastracea family, which grows mainly in Ethiopia, Kenya, and Yemen and at high altitude areas in South Africa and Madagascar. The plant is known by different names in different countries: Khat in Ethiopia, Qat in Yemen, Mirra in Kenya and Qaad or Jaad in Somalia, but in most of the literature it is known as Khat [12]. The leaves of the Khat plant contain alkaloids structurally related to amphetamine [13]. In Africa chewing of Khat among children is not encouraged, and fathers will often continue to discourage their sons well into adult life [14].

The youth constitutes the population aged 15 - 24 years. Worldwide, there are more than one billion people within the ages of 15 - 24 years, most of who live in developing countries. Young people constitutes one-third of the total population in Ethiopia [15]. Hard drugs like heroin and cocaine are very rarely available in Ethiopia. However, Khat, a locally produced psycho-stimulant is commonly and widely used in the country [11]. Only 0.7\% of in-school youth reported use of substances other than Khat, compared to 5.1\% for out-of-school youth [11].

According to Ethiopian Demographic and Health Survey, eleven percent of women and twenty eight percent of men reported that they had ever chewed Khat. Among both women and men, this proportion increases with age. Among women, chat consumption is higher in rural areas than that in urban areas (12 percent versus 7 percent); while among men there is no marked difference by place of residence. The percentage who ever chewed chat is highest among women with no education (14 percent) and among men with more than secondary education (32 percent) [16]. Figure 1 and Figure 2 show tip of Khat which will be chewed and bundle respectively.

The reported reasons for chewing Khat include religious prayer, to pass time, to accompany or socialize with family members, and to get more concentration at work [4]. "To keep alert while reading” and "for relaxation with friends" were the main reasons for starting chewing, $40.5 \%$ and $33 \%$, respectively [17].

According to study conducted among the staff of Jimma University, the reasons for chewing Khat were to increase performance (58.5\%) followed by relaxation (39.8\%) and socialization (18.7\%) [18]. The study done by Gorfu M showed that the college students are using Khat to overcome academic stressful work (40\%); the next $31.4 \%$ and $23.8 \%$ reported that mostly they are using Khat to enjoy with their friends and to be free from anxiety, 


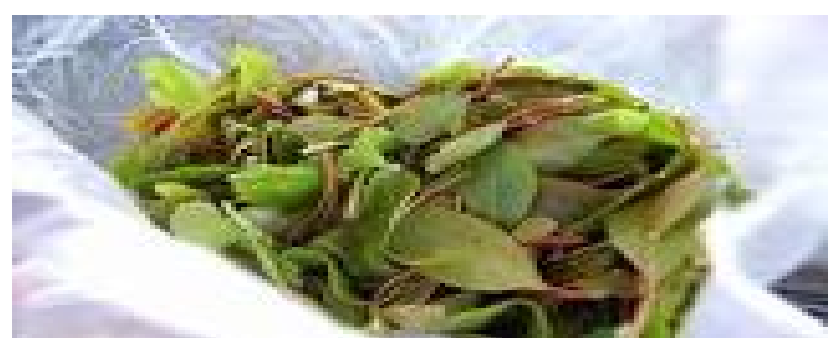

Figure 1. Tip of Khat prepared to be chewed (source: www.blackgoldfoundation.org, accessed on September 10, 2014).

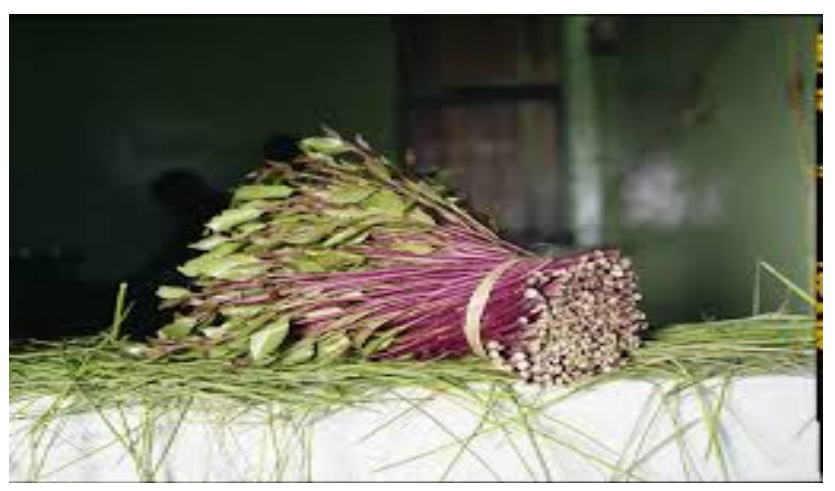

Figure 2. Bundle of Khat (source: www.blackgoldfoundation.org, accessed on September 10, 2014).

respectively [1]. "To keep alert while reading” and "for relaxation with friends" were the main reasons for starting Khat chewing [19]. The main reasons reported for chewing Khat included for effective reading and studying (68\%), for enjoyment (63\%) and to get rid of sleeplessness (43\%) according to study among undergraduate students of Addis Ababa University [20]. The subjective reasons given for Khat chewing were "to get concentration", "peer pressure" and "for enjoyment" among others as shown by study in Dire Dawa [21]. Relief from academic stress 41 (51.8\%), for relaxation 27 (34.1\%) and socialization 17 (21.5\%) were among the reasons for Khat chewing [22].

Khat typically is ingested while chewing the leaves. After ingesting Khat, the chewer experiences an immediate increase in blood pressure and heart rate [2]. Substance abuse is generally believed to be one of the associated factors for sexual risk behaviour in HIV transmission [11]. Grandiose fantasy 138 (65.7\%), depression 92 (43.8\%), anxiety 107 (50.9\%) and impotency 70 (33.3\%) were reported due to Khat use [1]. Local interviewers found that rates of severe disability due to mental disorders were $8.4 \%$ among males (above the age of 12); of these, $83 \%$ had severe psychotic symptoms [23].

About $40 \%$ of those out-of-school youths who chewed Khat reported that it increased their sexual desire [24]. Furthermore, a significant association was observed between frequencies of Khat chewing and intake of alcohol [24]. Study done on Khat chewing and mental distress showed that over a quarter of the study participants (25.8\%) were found to have mental distress due to Khat chewing [25].

Among Khat chewers, 34 (27.6\%) were chewing 2 - 3 times per week [18]. Over 23\% of out-of-school youth used Khat every day or once weekly while only 7.5\% of in-school youth did so [11]. Of the chewers, 89 (20.9\%) chewed Khat daily [21]. Approximately $16 \%$ of the men chewed Khat 1 or more days every week; $5 \%$ chewed Khat daily [26]. More than four hours were spent by 26 (32.9\%) of the respondents per ceremony for Khat chewing [22].

The median duration (years) of chewing was 20 years [4]. The peak age of Khat chewing was found to be between 18 and 44 years [18]. The habit of Khat chewing was more frequent in the age group between 16 and 45 years and less common above the age of 55 [27]. Median age at start of chewing was 22 years (range, 12 - 42 years) among current chewers [26]. The mean (SD) age of chewing debut was 15.1 (2.33) years [21].

Seventy-four (40.2\%) have started Khat chewing before four years [18]. Among Khat chewers, 57.8\% were 
regular daily Khat chewers [27]. One hundred and thirty four (45.6\%) of the lifetime chewers started chewing when they were senior secondary school students and 52 (17.7\%) of the lifetime chewers started chewing during their first year at college [17]. Forty percent of the chewers started chewing while they were in college or university, $20.7 \%$ as government employees, $17.4 \%$ at senior secondary school, $14.2 \%$ at elementary school, $3.9 \%$ at junior high school and 3.9\% of them started during childhood [18]. Twenty-four (40.0\%) of the instructors started Khat chewing while they were in senior high school or first year college [19].

The amount of Khat consumed at a time was estimated per cost in birr, and $76.2 \%$ of the chewers consumed Khat that costs 1 - 5 birr [27]. The average amount of Khat chewed each day by one individual was $52.4 \mathrm{gm}$ and the average money spent per day by one chewer was 2.9 birr [17]. The amount of Khat consumed at a time was estimated per cost in birr, and fifty one (41.5\%) of the chewers consumed Khat that costs 3 - 5 birr per ceremony [18]. The average amount of money spent each day by one Khat chewer was 3.0 birr [19]. Out of those who chewed Khat, 144 (33.6\%) spent more than 26 birr (mean = 26.4 birr) per week [21]. Twenty three (29.1\%) of the chewers consume Khat that costs 15 - 20 birr [22].

Most (72.1\%) of the chewers chew Khat with friends, $13.6 \%$ chew alone, $13.6 \%$ chew with spouse and $0.7 \%$ chew with their parents [18]. Seventy-eight percent got the money from their family and 22\% from their friends [21]. Two hundred sixty four of the students had family members who chew Khat [17]. Forty seven (59.5\%) were from Khat chewing families [22]. Only 9.0\% chewers reported that they might be addicted to Khat, while another $45 \%$ claimed that they might have some habit of chewing, but no addiction [4].

Out of the total studied subjects, $63.7 \%$ said yes for coffee consumption, of which $24.2 \%$ were found to be Khat chewers or drink coffee during Khat chewing and $14.7 \%$ of the Khat chewers ingested alcohol after chewing [27]. Thirty eight (30.9\%) of the chewers smoked cigarettes while chewing Khat and the habits of Khat chewing and cigarette smoking were found to have a statistically significant association. Fifty two (42.3\%) of the chewers drank coffee while chewing but no statistically significant association was found between Khat chewing and drinking coffee and 73 (59.4\%) took alcohol after Khat chewing [18]. The students reported that alcohol consumption (75\%) and cigarette smoking (63\%) were the main additional substances used after Khat chewing [20]. In addition to Khat chewing, 186 (43.5\%), 142 (33.3\%) and 128 (29.9\%) students drank alcohol, smoked cigarettes and used shisha respectively [21]. The life time and current shisha smoking prevalence in the schools was $12.8 \%$ and $7.6 \%$, respectively [28]. Thirty eight (48.1\%) of the chewers smoked cigarette, 70 (88.6\%) drank coffee and 7 (8.9\%) took other substances like hashish, diazepam and shisha during chewing. Twenty (25.3\%) reported to drink alcohol after Khat chewing. Twenty three (76.7\%) of the respondents who were getting $>500$ birr per month were Khat chewers [22].

Addiction and Gastro-Intestinal Tract (GIT) problems like constipation were mentioned as the main health problems of chewing Khat, 47.3\% ( $\mathrm{n}=423)$ and 33.4\% $(\mathrm{n}=299)$, respectively [17]. Many instructors believed that Khat chewing had health risks, $79.05(\mathrm{n}=143)$. Mental problems and GIT problems were mentioned as the main health problems of chewing Khat, $60.1 \%$ and $44.8 \%$, respectively. One hundred and forty seven (81.2\%) instructors believed that chewing Khat causes socio-economic problems [19]. All of the respondents said that Khat chewing has health risk. Sleep disturbance 177 (74.0\%) and psychosis 167 (70\%) were few among other health problems reported by respondents, considered to be the result of Khat chewing [22].

Few reports could be found in the literature on the prevalence of Khat among the university students. Milaat et al. (2005) reported that current Khat prevalence among the general population in Jazan area (Saud Arabia) was 48.7 percent [29]. The overall prevalence of Khat chewing in all the studied population of students was $21.4 \%$. Khat prevalence was high in secondary schools (21.5\%) compared to the colleges (15.2\%). The life time prevalence rate of Khat chewing in the colleges was: $41.90 \%$ in Boys Health College, $38.20 \%$ in Engineering and Computer College, 21.40\% in Boys College of Medicine, 7.20\% in Samtah Girls Education, 4.80\% in Sabiya Girls Education, 3.50\% in Jazan Girls Education and 1.40\% in Farsan Girls Education [30].

In a study conducted in Jimma Town in 2000, the current prevalence of Khat chewing was found to be $30.6 \%$ [27]. The prevalence of cigarette smokers in the study was $17.2 \%$, of which $32.4 \%$ of the smokers were found to be Khat chewers [27]. The prevalence rates of Khat chewing in Butajira and Adamitulu were 50\% and 31.7\% respectively [5]. Eighteen percent of men and 2\% of women reported current Khat chewing [26]. Four hundred fifty three of the twelve hundred participants were chewing Khat giving the current prevalence rate 37.8\% [25].

One study revealed that the prevalence of Khat chewing among secondary school students in south-western Ethiopia was $64.9 \%$ [31]. Among in-school youth, over $90 \%$ did not use Khat or alcohol, while among the out-of-school youth close to 73\% did not use Khat or alcohol [11]. A total of 427 (24.2\%) students ever chewed 
Khat [21]. The life time Khat chewing prevalence in the schools was $18.4 \%$ and the current prevalence was $10.9 \%$ [28]. The percentages of ever use of Khat were $9.2 \%, 35.6 \%$ and $31 \%$, in urban governmental high school, private high school, and Butajira rural governmental high school, respectively [8].

The life time prevalence of Khat chewing was found to be $32.6 \%$ and the current prevalence was $21.0 \%$ [19]. In a study conducted in 2003 among staffs of Jimma University in northwest Ethiopia, the lifetime prevalence of Khat chewing was found to be $46 \%$ while the current prevalence of Khat chewing was $30.8 \%$ [18].

The lifetime prevalence of Khat chewing was $26.7 \%$. One hundred twenty students (10.9\%) were both life time smokers and chewers. The life time prevalence rate of Khat chewing in GCMS (Gonder College of Medical Sciences), GCTE (Gonder College of Teacher Education), BUENGF (Bahr Dar University Engineering Faculty, and BUEDUCF (Bahr Dar University Education Faculty) was 27.4\%, 23.2\%, 27.5\% and 27.2\%, respectively. There were 18 life time chewers. The current prevalence rate of Khat chewing was $17.5 \%$ among college students of North West Ethiopian 2001 [17]. The prevalence rate of current use of Khat among medical and paramedical students in north-western Ethiopia [32] was 22.3\%. About $14 \%$ of the participants reported lifetime use of Khat. Only 7\% of the participants reported the use of Khat within the last 12 months; about $4 \%$ did it in the past week and 2\% reported the current use of Khat [20]. A study conducted in Jimma University showed that the current prevalence of Khat chewing was 33.1\% [22].

Khat chewing habit emerged as a significant risk predictor for HIV (Human Immune Virus) infection along with other influencing factors, viz. age, sex, religion, educational and marital status, and multiple sexual practices. The risk of being HIV positive increases 1.97 times by Khat chewing; as much as 4.68 times through multiple sexual practice; 2.05 times among the age group at or above 31 years; and 2.71, 2.67, 2.09, and 1.62 times among the females, the less educated, among the married, and the Christians, respectively [33]. Being male sex, being single and having sex with commercial sex workers were positively associated with Khat chewing [34].

The presence of family members who chew Khat was a risk factor for chewing Khat [17]. Instructors from the GCTE, those with high income, Muslim and instructors who had family members who chew Khat were found to be at higher risk of chewing Khat [19]. It was noted that the use of Khat was reported to be higher among male than that among female students [20].

Compared to Christians and Muslims other religious groups were at higher risk of chewing. There was no statistically significant difference in chewing habit between the different faculties and regions [17]. The risk of chewing increases with increasing year of study and age and males were at higher risk compared to female students [17]. Male sex and being Muslim were significantly associated with Khat chewing [18].

No association was found between Khat chewing and membership of specific ethnic group, age group, marital status and educational level [18]. There was a significant association of Khat chewing habit among Muslims compared with Christians and Khat chewing was found to be commoner among males than females [27]. The presence of a strong association between Khat chewing and alcohol consumption was observed. The combined use of both drugs seemed to have a more amplifying effect on the incidence of rate of HIV infections than either drug has individually [33]. The use of one or more substances was markedly higher among men than women [26]. There were 151 (3.8\%) female Khat chewers and 1783 (37.70\%) male Khat chewers. Significant difference was found between male and female Khat chewers [30].

Being Muslim was strongly and positively associated with Khat use in the past year, but students who reported business as their parent's main source of income were less likely to consume Khat than students who reported other source of income for their parents. Students who reported having a friend who currently chewed Khat were about eight times more likely to chew Khat than those students who reported no such friend (adjusted OR (Odds Ratio $)=8.08$, 95\% CI (Confidence Interval) $=2.84-22.98)$ [20]. The prevalence of Khat chewing occurs across all years of study, although it is higher among clinical students than pre-clinical ones [20]. It was found that those students who reported friend's use of alcohol, Khat and cigarette smoking were more likely to be users of either one or all of the above substances than those students whose friends were non-users [20]. Sex was related with alcohol use and cigarette smoking, yet it was not related with Khat use [20].

Khat chewing was significantly associated with male gender, peer influence and similar habit among family members, and being a Muslim [21]. Current substance use was statistically associated with gender, grade in school, religion, ethnicity, presence of income, peer and social pressures, substance use by significant others, knowledge and attitudes about substance use, and parental factors [28]. The habit of Khat chewing was higher in males than females [22]. Khat chewing had a significant association with high income, smoking habit, Oromo ethnicity, Muslim religion and coffee drinking habit [22]. 
The objective of this study was to assess the prevalence of Khat chewing and associated factors among undergraduate Adama University students, Ethiopia.

\section{Methodology}

The study was conducted at Adama University, which is located at 100 kilometres to the east of Addis Ababa, the capital city of Ethiopia. Adama town has a growing trend of infrastructure, utilities and large labour force. It falls within the low land zone with an average annual temperature of 21 degree Celsius. Based on the 2007 census, in 2010 the population of the city was estimated to be 280,000. The major sources for Khat to the town are from Wondogenet and Harar. There are two Khat distributing centers in the town: Arada and Gimbi Gabaya. From these sources it will be again redistributed to Khat selling shops and neighbour towns (Asella, Gofa, Doni, Wonji, and Wolenchit) [35].

Adama University is one of the universities which is found in Ethiopia. The university gives teaching learning process in different programmes: regular, extension and summer. The total number of regular undergraduate students in the academic year of 2011/12 was 13930. The University has six schools namely school of engineering and information technology, school of business, school of humanity and natural sciences, school of pedagogy, school of agriculture and school of health. The study was conducted in January, 2012 G.C (Gregorian Calendar).

Quantitative higher teaching institution based cross-sectional study design was conducted. The source population were all Adama University regular undergraduate students who were registered as second year and above during the academic year of 2011/2012.

Adama University students randomly selected from the six departments and who completely filled the selfadministered questionnaire were the study population. Critically ill students during data collection time were excluded from study. In addition, first year, extension, summer, distance education and post graduate students were excluded.

Sample size (n) required for this study was calculated by using single population proportion (p) formula to be 764 by taking margin of error to be $4 \%$ and, 95\% confidence interval and the prevalence of Khat chewing among college students of North West Ethiopia in 2001 which was $17.5 \%$. Finally, the sample size was 764 by considering non-response rate $10 \%$ and design effect 2 .

Multi stage sampling technique was used to select the respondents of the study. First, among the six schools in Adama University, one department was selected by using simple random sampling (SRS) method from each school. Sample size was proportionally allocated for the selected departments based on their class size and academic years of the study. Secondly, from the selected departments, by using the students' name list from the registrar as a sampling frame, the respondents were selected by a simple random sampling method for the selfadministered questionnaire.

The dependent variable was Khat chewing while the nindependent variables were age, sex, ethnicity, religion, marital status, department/school, academic year, income of family and the students, peer pressure, family history of Khat chewing and availability of Khat.

The final English version of the questionnaire was developed after extensive revision of relevant literature on the subject and WHO (World Health Organization) student drug-use questionnaire to ensure reliability. Data was collected from sample students using structured self administered questionnaire having two parts. The first part contains general information including socio demographic characteristics of the students and their family where as the second part contains the questionnaire which assesses Khat chewing condition of the students and their family's history of Khat chewing. Two versions of the questionnaire were used: an English version and an Amharic language version. Amharic version was made available to students.

The data collection was facilitated by four grade twelve completed students and supervised by two Bachelor of Science (BSc) holders in health sciences. The sample size for each randomly selected department was predetermined proportionally. Therefore the number of students in the study sample was known for each class. The time elapsed (used) for filling questionnaire in one class by average was 15 - 25 minutes. The ID (Identification) number of the students in the sample was posted in the class. Then the data collectors inform the students about the objective of the study and administered the questionnaire by cross checking their ID number. Finally, the data collectors collected the questionnaire and the supervisors took the questionnaire by checking the completeness.

To assure the data quality high emphasis was given in designing data collection instrument. Pre-test was done in Ambo University, prior to five days of the actual data collection day on 30 students, followed by modification. 
Proper instruction was given before the survey as to the importance of the study for the students. During data collection, the supervisors received questionnaires from data collectors and reviewed for completeness, accuracy, and consistency.

The collected data was reviewed and checked for completeness before data entry; the incomplete data was discarded. Complete data was coded and entered into EPI info version 3.5.1 and transported to SPSS version 16. The analyses was composed of two parts, descriptive and analytical statistics. Descriptive analysis of frequency, percentage, mean, median and standard deviation were applied for general characteristics, prevalence of Khat chewing. Logistic regression was applied to find the relationship between outcome (dependent) variable and independent variable. Crude logistic regression was used to see relationship between one independent variable with outcome at time and adjust logistic regression was used to see relationship between many independent variables with outcome variable after controlling confounding factors. Significance level and association of variables were tested by using 95\% Confidence Interval (CI) and odds ratio. Level of significant was set at 5\%.

Ethical clearance letter was obtained from Research and Ethics Committee (REC) of School of Public Health, Addis Ababa University. A written consent was obtained from Adama University. Additionally verbal consent information was explained to the students before delivering questionnaire. The students had right to refuse join this study without any effects on their study's result and no need to explain the reason. Students were informed that data will be used for research's purpose only. To keep confidentiality, no need to write their name and personal identification.

The result of this study will be disseminated or communicated to Addis Ababa University School of Public Health, Federal Ministry of Education, Ministry of Health, Adama Town Administrative Bureau, Adama University, local institutions and other concerned bodies through reports and publication on an appropriate journal.

\section{Result}

Of the total 764 questionnaires administered, 728 were completed and returned making a response rate of 95.3\%. The study population included more males (87.5\%) than females. The students age range from 18 to 35 years, with the mean of 21.84 years (SD (Standard Deviation) $= \pm 1.67)$ and the majority $633(87 \%)$ were within the age of 20 - 24 years old as shown in Table 1.

With regard to the department of the students, most students 304 (41.8\%) were from electrical engineering department and followed by business administration department students 105 (14.4\%). From total of students involved in the study second year students account 286 (39.3\%) and followed by third year students that account 276 (37.9\%) as shown in Table 1.

The main ethnicity group was Oromo which account for 315 (43.27\%) and followed by Amhara which was 242 (33.24\%). About 55.9\% and 25.1\% of the sample were Orthodox Christian and Muslim, respectively, followed by Protestant Christian (15.7\%). Most of the students involved in the study were unmarried which account $673(92.4 \%)$ as shown in Table 1.

When the students were asked about their source of monthly income, they revealed that 676 (92.9\%) of the students got money from the family, 71 (9.8\%) from friends, 182 (25\%) from relatives and 107 (14.7\%) from their own (the percent does not add up hundreds because one student can answer more than one alternatives). Similarly, concerning their monthly pocket money, 5.6\% of the students did not report their estimated money. From those who revealed it, 39.6\% reported birr 100.00 - 299.00 and $54.8 \%$ indicated birr 300.00 or more. The average monthly income reported was $351.90(\mathrm{SD}= \pm 210.15)$ birr. The minimum and maximum amounts of monthly pocket money were 100 and 1200 birr respectively. Government employment (27.9\%), business (27.3\%), and agriculture-based (38.0\%) were the main reported source of parents' income as depicted in Table 1.

The lifetime prevalence of Khat chewing was found to be $27.7 \%$ while the current prevalence of chewing was $20.7 \%$ and briefly presented in Table 2 . The life time prevalence of Khat chewing among males (21.5\%) was higher than that of females (6.2\%). Similarly the current prevalence of Khat chewing was higher for male students (16.9\%) when compared to female students (3.8\%).

The life time prevalence rate of Khat chewing in the departments was: $36.5 \%$ in natural resource management, $33.3 \%$ in electrical electronics, $32.7 \%$ in law, 25.7 in business administration, $25.3 \%$ in electrical engineering and 24.3 in medicine. The current prevalence of Khat chewing according to the year of study was: $21.3 \%$ in second year, $22.9 \%$ in third year, $16.3 \%$ in fourth year and $16.1 \%$ in fifth year students. The current prevalence rate of Khat chewing in natural resource management, in electrical electronics, law, in business administration, in electrical engineering and in medicine was $32.7 \%, 26.7 \%, 24 \%, 21 \%, 19.7 \%$ and $10.7 \%$, respectively. 
Table 1. Socio-demographic characteristics of undergraduate Adama University students, Adama, Ethiopia, January 2012.

\begin{tabular}{|c|c|c|}
\hline Variables & Frequency $N=728$ & $\%$ \\
\hline \multicolumn{3}{|l|}{ Age (years) } \\
\hline $15-19$ & 64 & 8.7 \\
\hline $20-24$ & 633 & 87.0 \\
\hline 25 or more & 31 & 4.3 \\
\hline \multicolumn{3}{|l|}{ Sex } \\
\hline Male & 637 & 87.5 \\
\hline Female & 91 & 12.5 \\
\hline \multicolumn{3}{|l|}{ Department of the student } \\
\hline Natural resource management & 52 & 7.2 \\
\hline Medicine & 103 & 14.1 \\
\hline Law & 104 & 14.3 \\
\hline Electrical engineering & 304 & 41.8 \\
\hline Business administration & 105 & 14.4 \\
\hline Electrical electronics & 60 & 8.2 \\
\hline \multicolumn{3}{|l|}{ Year of the study } \\
\hline Second year & 286 & 39.3 \\
\hline Third year & 276 & 37.9 \\
\hline Fourth year & 104 & 14.3 \\
\hline Fifth year & 62 & 8.5 \\
\hline \multicolumn{3}{|l|}{ Marital status } \\
\hline Never married & 673 & 92.4 \\
\hline Ever married/cohabiting & 55 & 7.6 \\
\hline \multicolumn{3}{|l|}{ Religion } \\
\hline Orthodox Christian & 407 & 55.9 \\
\hline Protestant Christian & 114 & 15.7 \\
\hline Muslim & 183 & 25.1 \\
\hline Others & 24 & 3.3 \\
\hline \multicolumn{3}{|l|}{ Ethnicity } \\
\hline Amhara & 242 & 33.3 \\
\hline Oromo & 315 & 43.3 \\
\hline Gurage & 70 & 9.6 \\
\hline Tigre & 78 & 10.7 \\
\hline Others & 23 & 3.2 \\
\hline Monthly pocket money & $N=686$ & \\
\hline 100 - 299 birr & 398 & 59.1 \\
\hline 300 or more birr & 288 & 40.9 \\
\hline \multicolumn{3}{|l|}{ Family's main source of income } \\
\hline Daily labourer & 26 & 4.0 \\
\hline Government employee & 204 & 27.9 \\
\hline Business & 199 & 27.3 \\
\hline Agriculture-based & 279 & 38.0 \\
\hline Others & 20 & 2.7 \\
\hline
\end{tabular}


Table 2. Prevalence of Khat chewing among undergraduate students of Adama University, Adama, Ethiopia, January 2012.

\begin{tabular}{|c|c|c|c|c|c|c|c|c|c|c|}
\hline \multirow{3}{*}{$\begin{array}{c}\text { Prevalence of Khat } \\
\text { chewing }\end{array}$} & \multicolumn{4}{|c|}{ Khat chewers } & \multicolumn{4}{|c|}{ Non-Khat chewers } & \multirow{2}{*}{\multicolumn{2}{|c|}{ Total }} \\
\hline & \multicolumn{2}{|c|}{ Male } & \multicolumn{2}{|c|}{ Female } & \multicolumn{2}{|c|}{ Male } & \multicolumn{2}{|c|}{ Female } & & \\
\hline & No & $\%$ & No & $\%$ & No & $\%$ & No & $\%$ & No & $\%$ \\
\hline Lifetime prevalence & 157 & 21.6 & 45 & 6.2 & 480 & 65.9 & 46 & 6.3 & 202 & 27.7 \\
\hline One year prevalence & 150 & 20.6 & 41 & 5.6 & 487 & 66.9 & 50 & 6.9 & 191 & 26.2 \\
\hline Current prevalence & 123 & 16.9 & 28 & 3.8 & 514 & 70.6 & 63 & 8.7 & 151 & 20.7 \\
\hline
\end{tabular}

Table 3 shows, among current Khat chewers, 67 (44.4\%) were chewing Khat on occasional base. Most (53\%) of the chewers chew Khat with friends in the university, 23.8\% chew with friends out of the university, 21.8\% chew alone and $1.4 \%$ chew with their parents. Concerning the accessibility of Khat almost above half of the current chewers 77 (51\%) bought it from in front of the university. Sixty four of the students (42.4\%) got it in the town while ten of the students obtain it from their friends.

Table 3 shows, Eighty one (53.6\%) of the Khat chewers smoke cigarette while chewing and seven (4.6\%) took hypnotics after Khat chewing. Ninety (59.7\%) of the chewers drink hot drinks like coffee while chewing and $64(42.4 \%)$ took alcohol after Khat chewing. Other substance use was also observed in 66 (43.8\%) of the students. Many of the students 137 (90.8\%) used water by the time of Khat chewing. During Khat chewing 76 (50.3\%) of current chewers used sugar and 74 (49\%) used soft drinks. Majority of the current chewers (43.7\%) chew Khat in their dormitory. Only males (6.6\%) were found to be chewers in the video house.

On average 19.78 birr (SD $= \pm 7.245$ ) is spent by a Khat chewer per ceremony. The minimum and the maximum amount of money spent in a ceremony of Khat were 7 and 40 birr, respectively. Four hundred and eighty two (66.2\%) of the students had a family who chew Khat and 493 (67.75\%) also had friends who chew Khat.

Table 4 shows the time when the students started Khat chewing. Accordingly, majority of the students (67.2\%) started Khat chewing when they were in grade eleven or twelve or first year in the university. Almost $10 \%$ of the students started Khat chewing by the time they were second year university students. Five percent of the students started Khat chewing below high school level. Only three percent of the students started Khat chewing above second year or other time.

Life time chewers gave various reasons for chewing Khat. The main reason mentioned was to increase performance and concentration on study (68.3\%) followed by peer pressure (56.4\%) and enjoyment (relaxation) (45\%). Only 6 (3\%) of students chew Khat for the purpose of enhancing sex.

Table 5 shows the risk of Khat chewing. Accordingly, many students from that of life time chewers stated that Khat chewing have problems, 115 (57\%). From the problems mentioned by the students, health risks (94.8\%) were the major one. Economic problem was stated by 70 students (60.9\%) followed by social problems (34.8). Twenty of the students mentioned that chewing Khat has educational problems. Teeth problem and decrement in sexual feeling were mentioned as the main health problems of chewing Khat, $56.9 \%$ and $54.1 \%$, respectively. The other health problems mentioned by the students were weight loss (49.5\%), gastrointestinal problems (34.9\%) like constipation, addiction (28.4\%) and increment in sexual feeling (9.2\%). Disagreement with the family members, rejection by the society and criminal activity were the mentioned social problems.

Table 6 shows the association between dependent and independent variables. According to binary logistic regression, being male, being less than 20 years, being medicine department and having more than or equal to 300 birr for pocket monthly money showed association. However, the rest did not show any association before and after adjustment.

To minimize the risk of confounder for dependent variables multiple logistic regressions were used. Having families who are chewing Khat had association with Khat chewing of the students in the university. It had showed significant association at P-value of 0.007 with COR (Crude Odds Ratio) $(95 \% \mathrm{CI})=1.65(1.15,2.39)$ and P-value of 0.009 with AOR (Adjusted Odds Ratio) $(95 \% \mathrm{CI})=1.72(1.14,2.59)$. Students whose family has the history of Khat chewing were 1.72 times likely to chew Khat than the students whose family didn't, according to Table 6. The socio-demographic factors of being male and having pocket monthly income of equal to or more than 300 birr showed significant association with Khat chewing. It showed significance at P-value 0.013 with COR $(95 \%$ CI $)=1.86(1.14,3.02)$ and P-value 0.023 with AOR $(95 \%$ CI $)=1.95(1.10,3.47)$. The students 
Table 3. Patterns of Khat chewing among undergraduate Adama University students, Adama, Ethiopia, January 2012.

\begin{tabular}{|c|c|c|c|c|c|c|}
\hline \multirow{2}{*}{ Pattern of Khat chewing } & \multicolumn{2}{|c|}{ Male } & \multicolumn{2}{|c|}{ Female } & \multicolumn{2}{|c|}{ Total } \\
\hline & No & $\%$ & No & $\%$ & No & $\%$ \\
\hline \multicolumn{7}{|l|}{ Chewing frequency } \\
\hline Daily & 26 & 17.2 & 4 & 2.6 & 30 & 19.8 \\
\hline One to three times a week & 43 & 28.5 & 11 & 7.3 & 54 & 35.8 \\
\hline Occasionally & 54 & 35.8 & 13 & 8.6 & 67 & 44.4 \\
\hline \multicolumn{7}{|l|}{ Where Khat is chewed } \\
\hline In the dorm & 52 & 34.4 & 14 & 9.3 & 66 & 43.7 \\
\hline In the video house & 10 & 6.6 & 0 & 0 & 10 & 6.6 \\
\hline In Khat selling house & 46 & 30.4 & 9 & 6.0 & 55 & 36.4 \\
\hline In relatives home & 14 & 9.3 & 4 & 2.6 & 18 & 11.9 \\
\hline Other place & 1 & 0.7 & 1 & 0.7 & 2 & 1.4 \\
\hline \multicolumn{7}{|l|}{ With whom Khat is chewed } \\
\hline Alone & 25 & 16.5 & 8 & 5.3 & 33 & 21.8 \\
\hline With friends in the university & 67 & 44.4 & 13 & 8.6 & 80 & 53 \\
\hline With friends out of the university & 29 & 19.2 & 7 & 4.6 & 36 & 23.8 \\
\hline With family & 2 & 1.4 & 0 & 0 & 2 & 1.4 \\
\hline \multicolumn{7}{|l|}{ Substance use during/after Khat chewing } \\
\hline Cigarette smoking & 67 & 44.3 & 14 & 9.3 & 81 & 53.6 \\
\hline Hot drinks like coffee use & 72 & 47.8 & 18 & 11.9 & 90 & 59.7 \\
\hline Alcohol intake & 58 & 38.4 & 6 & 4.0 & 64 & 42.4 \\
\hline Hypnotics use & 5 & 3.3 & 2 & 1.3 & 7 & 4.6 \\
\hline Other substances use & 44 & 29.2 & 22 & 14.6 & 66 & 43.8 \\
\hline
\end{tabular}

Table 4. The year in which undergraduate Adama University students started Khat chewing, Adama, Ethiopia, January 2012.

\begin{tabular}{|c|c|c|}
\hline \multirow{2}{*}{ Time } & \multicolumn{2}{|c|}{ Life time Khat chewers; $n=202$} \\
\hline & Number & Percent \\
\hline Grade 1 - 6 & 4 & 2 \\
\hline Grade 7 - 8 & 6 & 3 \\
\hline Grade 9 - 10 & 30 & 14.9 \\
\hline Grade 11 - 12 & 60 & 29.7 \\
\hline First year in the university & 76 & 37.5 \\
\hline Second year in the university & 20 & 9.9 \\
\hline Third year in the university & 4 & 2 \\
\hline Fourth year in the university & 1 & 0.5 \\
\hline Fifth year in the university & 0 & 0 \\
\hline Other time & 1 & 0.5 \\
\hline
\end{tabular}


Table 5. Health risks of Khat chewing mentioned by undergraduate students of Adama University, Adama, Ethiopia, January 2012.

\begin{tabular}{ccc}
\hline Health risks & Number $(\mathbf{n}=\mathbf{1 0 9})$ & Percent \\
\hline Addiction & 31 & 28.4 \\
Loss of weight & 54 & 49.5 \\
Gastrointestinal problems & 38 & 34.9 \\
Affect teeth & 62 & 56.9 \\
Decrease sexual feeling & 59 & 54.1 \\
Increase sexual feeling & 10 & 9.2 \\
\hline
\end{tabular}

Table 6. Relationship between Khat chewing and factors like socio-demographic, academic and environmental factors among Adama University undergraduate students, Adama, Ethiopia, January 2012.

\begin{tabular}{|c|c|c|c|c|c|}
\hline \multirow{2}{*}{ variables } & \multicolumn{2}{|c|}{ Khat chewing } & \multicolumn{2}{|c|}{ OR (95\% CI) } & \multirow{2}{*}{ P-value } \\
\hline & Yes & No & Crude & Adjusted & \\
\hline \multicolumn{6}{|l|}{ Sex } \\
\hline Male & 123 & 514 & $1.86(1.14,3.02)^{*}$ & $1.95(1.10-3.47)^{*}$ & 0.023 \\
\hline Female & 28 & 63 & 1 & 1 & \\
\hline \multicolumn{6}{|l|}{ Age category } \\
\hline$<20$ years & 6 & 58 & $3.37(1.05,10.76)^{*}$ & $2.39(0.60,9.51)$ & 0.214 \\
\hline 20 - 24 years & 137 & 496 & $1.26(0.55,2.88)$ & $0.82(0.30,2.28)$ & 0.713 \\
\hline$>24$ years & 8 & 23 & 1 & 1 & \\
\hline \multicolumn{6}{|l|}{ Department } \\
\hline NRM $\diamond$ & 17 & 35 & $0.75(0.33,1.69)$ & $0.55(0.20,1.53)$ & 0.245 \\
\hline Medicine & 11 & 92 & $3.04(1.30,7.10)^{*}$ & $1.91(0.69,5.27)$ & 0.213 \\
\hline Law & 25 & 76 & $1.15(0.56,2.38)$ & $0.75(0.29,1.95)$ & 0.548 \\
\hline EEN $\diamond$ & 60 & 244 & $1.48(0.78,2.80)$ & $0.94(0.43,2.08)$ & 0.874 \\
\hline BA $\diamond \diamond$ & 22 & 83 & $1.37(0.65,2.88)$ & $1.15(0.47,2.83)$ & 0.768 \\
\hline $\mathrm{EE} \diamond \diamond \diamond$ & 16 & 44 & 1 & 1 & \\
\hline \multicolumn{6}{|l|}{ Year of study } \\
\hline Second year & 61 & 225 & $0.71(0.34,1.48)$ & $0.48(0.19,1.20)$ & 0.118 \\
\hline Third year & 63 & 213 & $0.65(0.31,1.35)$ & $0.48(0.19,1.22)$ & 0.120 \\
\hline Fourth year & 17 & 87 & $0.98(0.42,2.31)$ & $0.52(0.17,1.54)$ & 0.234 \\
\hline Fifth year & 10 & 52 & 1 & 1 & \\
\hline \multicolumn{6}{|l|}{ Marital status } \\
\hline Never married & 138 & 535 & $1.20(0.63,2.30)$ & $0.87(0.40,1.91)$ & 0.721 \\
\hline Ever married & 13 & 42 & 1 & 1 & \\
\hline \multicolumn{6}{|l|}{ Religion } \\
\hline Orthodox Christian & 89 & 318 & $0.72(0.24,2.15)$ & $0.81(0.25,2.60)$ & 0.722 \\
\hline Protestant Christian & 9 & 105 & $2.33(0.66,8.32)$ & $2.60(0.68,9.92)$ & 0.162 \\
\hline Muslim & 49 & 134 & $0.55(0.18,1.68)$ & $0.87(0.26,2.86)$ & 0.812 \\
\hline Other & 4 & 20 & 1 & 1 & \\
\hline
\end{tabular}


who were male chew Khat 1.95 times likely than female students. Similarly, the monthly pocket money of students getting equal to or more than 300 birr showed significant association with Khat chewing at P-value 0.019 with COR $(95 \%$ CI $)=1.55(1.07,2.23)$ and P-value 0.045 with AOR $(95 \%$ CI $)=1.52(1.01,2.28)$. The students who got pocket monthly income of equal to or more than 300 birr were 1.52 times likely to chew Khat than students getting less than 300 birr monthly pocket money as shown in Table 6.

Having a friend that chews Khat showed association at P-value 0.007 with COR $(95 \% \mathrm{CI})=1.69(1.17,2.44)$ and P-value 0.012 with AOR $(95 \% \mathrm{CI})=1.70(1.12,2.58)$. The students who report that their friends chew Khat were 1.70 times likely to chew Khat than students didn't have. Being medicine student showed significant association with Khat chewing before adjustment as depicted in Table 7.

Table 7. Relationship between Khat chewing and factors like socio-demographic, academic and environmental factors among Adama University undergraduate students, Adama, Ethiopia, January 2012.

\begin{tabular}{|c|c|c|c|c|c|}
\hline \multirow{2}{*}{ Variables } & \multicolumn{2}{|c|}{ Khat chewing } & \multicolumn{2}{|c|}{ OR (95\% CI) } & \multirow{2}{*}{ P-value } \\
\hline & Yes & No & Crude & Adjusted & \\
\hline \multicolumn{6}{|l|}{ Ethnicity } \\
\hline Amhara & 41 & 201 & $1.03(1.03,3.19)$ & $1.50(0.42,5.37)$ & 0.535 \\
\hline Oromo & 74 & 241 & $0.69(0.23,2.08)$ & $1.02(0.29,3.59)$ & 0.972 \\
\hline Gurage & 22 & 48 & $0.46(0.14,1.51)$ & $1.26(0.33,4.86)$ & 0.735 \\
\hline Tigre & 10 & 68 & $1.43(0.40,5.08)$ & $2.42(0.58,10.06)$ & 0.227 \\
\hline Other & 4 & 19 & 1 & 1 & \\
\hline \multicolumn{6}{|l|}{ Monthly pocket money } \\
\hline 300 or more birr & 75 & 331 & $1.58(1.10,2.27)^{*}$ & $1.52(1.01,2.28)^{*}$ & 0.045 \\
\hline 100 - 299 birr & 74 & 207 & 1 & 1 & \\
\hline \multicolumn{6}{|l|}{ Source of income } \\
\hline Family--Yes & 136 & 540 & $1.61(0.86,3.02)$ & $1.28(0.54,3.01)$ & 0.564 \\
\hline ------------No & 15 & 37 & 1 & 1 & \\
\hline Friend----Yes & 18 & 53 & $0.75(0.42,1.32)$ & $1.01(0.53,1.99)$ & 0.931 \\
\hline ----------No & 133 & 524 & 1 & 1 & \\
\hline Relatives------Yes & 52 & 130 & $0.55(0.38,0.82) \diamond$ & $0.58(0.37,0.91) \diamond$ & 0.018 \\
\hline ---------No & 99 & 447 & 1 & 1 & \\
\hline Own------------yes & 29 & 78 & $0.66(0.41,1.05)$ & $0.74(0.40,1.38)$ & 0.354 \\
\hline -----------No & 122 & 499 & 1 & 1 & \\
\hline \multicolumn{6}{|c|}{ Family's main source of income } \\
\hline Daily labourer & 5 & 24 & $1.20(0.28,5.16)$ & $1.16(0.23,5.97)$ & 0.869 \\
\hline Civil servant & 36 & 167 & $1.16(0.37,3.68)$ & $1.22(0.34,4.35)$ & 0.758 \\
\hline Merchant & 64 & 135 & $0.53(0.17,1.64)$ & $0.58(0.16,2.03)$ & 0.392 \\
\hline Farmer & 42 & 235 & $1.40(0.45,4.39)$ & $1.58(0.44,5.63)$ & 0.478 \\
\hline Other & 4 & 16 & 1 & 1 & \\
\hline Family chew Khat---Yes & 86 & 396 & $1.65(1.15,2.39)^{*}$ & $1.72(1.14,2.59)^{*}$ & 0.009 \\
\hline ------No & 65 & 181 & 1 & 1 & \\
\hline Friend chew Khat---Yes & 88 & 405 & $1.69(1.17,2.44)^{*}$ & $1.70(1.12,2.58)^{*}$ & 0.012 \\
\hline ------No & 63 & 172 & 1 & 1 & \\
\hline
\end{tabular}




\section{Discussion}

This study was to determine the prevalence of Khat chewing among undergraduate Adama University students. In addition the study also planned to see the association between Khat chewing and common socio demographic variables and other key factors which may be associated with Khat chewing.

In this study the lifetime, twelve months and current prevalence of Khat chewing among undergraduate Adama University students were found to be $27.7 \%, 26.2 \%$ and $20.7 \%$ respectively.

The result of the study was lower compared to the study done in Buta Jira which was $55.7 \%$ and $50.5 \%$ life time and current Khat chewers respectively [10]. According to study conducted in Jimma Town, the current prevalence rate of Khat chewing was 30.6\% [27]. Among 479 staff's of Jimma University, the lifetime prevalence of Khat chewing was 46\%, while the current prevalence of chewing was 30.8\% [18] and in study conducted among university instructors in Ethiopia the life prevalence rate of Khat chewing was found to be 32.6\% [19]. Other studies conducted on the prevalence of Khat chewing among high school students in south-western Ethiopia was 64.9\% [31]. In a survey conducted in one private high school in Addis Ababa and one governmental high school in Butajira, 35.6\% and 31.0\% of the students respectively reported ever chewing of Khat [8]. Among students at a college of Medical Sciences in north-west Ethiopia, it was reported that $22.3 \%$ of students were current Khat chewers [32], which showed high prevalence of Khat chewing. The possible reason might be the difference of instruments used to assess Khat chewing, the different characteristics of each school, its students and the target groups. Other reason might be due to the use different methodologies. These could be due to the availability of Khat, social acceptance to the habit and study time difference.

According to the result of study by Hussein M Ageely on the prevalence of Khat chewing in college and secondary school students of Jazan region, Saudi Arabia [30], the overall prevalence of Khat chewing in all the studied population of students was $21.4 \%$ and the prevalence was high in secondary schools (21.5\%) compared to the colleges (15.2\%) which was below this finding. The study conducted on drug use among one of urban governmental high school in Addis Ababa revealed 9.2\% ever use of Khat [8]. Almost a quarter of High School Students in Eastern Ethiopia were ever Khat chewers [21]. The lifetime and current prevalence of Khat chewing was found to be $26.7 \%$ and $17.5 \%$ respectively according to study among college students in North West Ethiopia [17] which was again below the prevalence of this study. Another study conducted on Substance use and its predictors among undergraduate medical students of Addis Ababa University in Ethiopia [20] reported the lifetime use of Khat and the use of Khat within the last 12 months was $14 \%$ and $7 \%$ respectively. The possible reason might be due to the different characteristics of schools, study time difference, accessibility of Khat to the universities, absence of involving all school or faculties even in one college or university and its students.

Khat chewing was also assessed among each departments of Adama University student even though there was scarcity of literature to discuss on each department. The life time prevalence of Khat chewing in engineering and computer college of Jazan region [30] was 38.2\% and that of Bahir Dar University engineering college was 27.5\% [17] of which both were greater than this study (25.3\%). Regarding medicine department, the life time prevalence of Khat chewing in Saudi Arabia and Gonder College of Medical Sciences of Ethiopia were 21.4\% and 27.4\% respectively and prevalence in this study was $24.3 \%$. The possible explanation for this difference may be sample size, culture, time and disciplines of the universities. Khat chewing in the last twelve months among pre-clinical and clinical medicine students in Addis Ababa University was 4.7\% and 12.6\% respectively [20]. However, in this study the prevalence was $20.8 \%$ and $16.1 \%$ among pre-clinical and clinical students respectively. The current prevalence of Khat chewing finding in this study was lesser among third year medical students than study conducted in Jimma University [22], which were 20.5\% and 27.3\% respectively. The reason might be due to different study subject and the different characteristics of schools.

In this study about $42.4 \%$ and $53.6 \%$ students drank alcohol and smoked cigarettes respectively in addition to Khat chewing. In addition to these substances, the students also used shisha, hashish, hot and soft drinks, sugar and groundnuts during or after Khat chewing. This result is in line with other studies [18] [20]-[22] [27] [28]. This act of behaviour may be the reason why the teeth of the students were affected. This might indicates that Khat chewing can be the entry point in order to use other substances.

On average one chewer spent 19.78 birr each day for chewing Khat. Almost irrespective of the target groups, the money spent for Khat is equal to or greater than the previous studies [17] [18] [21] [22] [27]. This indicates that the money spent by the students is high and may not be afforded by them. This might lead to social problems like theft, disagreement with family and in general rejection by the society. 
Majority of the students in this study started Khat chewing when they were at senior secondary school and first year university students. This result supports other studies [17]-[19]. This might be due to new environment, peer pressure, change in content of subject matter (vast in university), and change in teaching style. Of course, this time is in agreement with the main reason mentioned by the students to start Khat chewing: increase performance and concentration on study, peer pressure, enjoyment (relaxation) and relief from stress. The reasons mentioned by the students were almost similar with other studies conducted in schools/colleges [1] [17]-[22].

This study showed that the habit of Khat chewing was higher in males than females, which was in line with research findings reported in Jimma University students in 2008 [22], with study reported for college students in north west Ethiopia (OR = 3.69; 95\% CI = 2.10 - 6.26) [17], with male high school students in eastern Ethiopia which had higher odds (OR $=2.10 ; 95 \% \mathrm{CI}=1.50-2.93)$ of Khat chewing than female students [25]. A similar finding has been reported among college students in Saudi Arabia showing significant differences in chewing between males and females (P-value $<0.05$ ) [30]. This might be due to the common tendency of males to chew Khat compared to females and there is cultural influence on females not to chew Khat. In other hand the study from undergraduate students of Addis Ababa University [20] showed that no association between gender and Khat chewing.

The result of the study indicate high prevalence of Khat chewing with the factors monthly pocket money, family history of Khat chewing and friends history of Khat chewing. In this study monthly pocket money was associated with Khat chewing. This was consistent with a study conducted in Ethiopia on medical and health officer students which report that the students whose monthly income much birr were found to be chewers compared to those with lower income $(\mathrm{P}<0.0001)$ [22]. This indicates that having money may encourage students to chew Khat and to have friends easily. According to the Result from medicine students of Addis Ababa University, students who reported business as their parent's main source of income were less likely to consume Khat than students who reported other source of income for their parents [20]. But there was no association between the students' parent main source of income and Khat chewing in this study. This study showed that the students who got their monthly income from relatives were less likely to chew Khat than students who got from other sources (AOR $=0.58 ; 95 \% \mathrm{CI}=0.37-0.91$ ). This might be due to the reason that there will be a fear from students not to get additional source of money as they want.

In this study it was revealed that the presence of family members who chew Khat predisposes students to chew Khat. Likewise with the study in North West Ethiopia [17] and in Jazan region of Saud Arabia [30] that showed association of Khat chewing with family history of Khat chewing, but the study among medicine students of Addis Ababa in Ethiopia [21] in contrast to this finding had no association. This might be due to the influence of social environment and that students tend to imitate and practice what they observed from their parents.

Having a friend who chews Khat was associated with Khat chewing. Students those reported having friends who chew Khat were 1.70 times more likely chew Khat than students didn't report of having chewer friends. Previous studies also identified that friends' chewing of Khat was strongly associated with the chewing of Khat among university students, indicating the influence of peer pressure [20] [21].

In present study religion had no significant association with Khat chewing, but, study conducted among undergraduate students in Addis Ababa University showed being Muslim was strongly and positively associated with Khat chewing in the past year [20]. Another studies also showed association of Khat chewing with Muslim religion [17] [22].

In this study ethnicity did not showed significant association with Khat chewing. In contrast of different studies revealed association of religion with Khat chewing such study from Jimma University medical and health officer students [22]. In the present study even though there was no association between Khat chewing and year of study as well as age, the association was revealed among college students of North West Ethiopia [17].

The study of all years and departments in the undergraduate Adama University students was strength of the study. The study used double data entry method, collectors and supervisors were trained, pre-test was done and equal chance was given for the sample attendant.

This study was not free of limitations. The limitations included the collection of data was based on self-report of the students and may be subjected to recall bias and under-reporting of Khat chewing due to social desirability bias. This is descriptive cross-sectional study that shows only point prevalence of Khat chewing and also inability to draw cause-effect associations between the studied variables. Other limitation with self reported questionnaires was inaccurate reporting. 


\section{Conclusion}

According to the findings of this study, the lifetime, twelve months and current prevalence of Khat chewing among undergraduate students of Adama University was 27.7\%, 26.2\% and 20.7\% respectively. The magnitude of Khat chewing among undergraduate students was considerable compared to most of studies done among college and university students, but lower than the findings of other studies that reported for adolescents and young adults (community based studies). Male sex, having monthly pocket money of $\geq 300.00 \mathrm{ETB}$, having chewer friend and parent were predictors of Khat chewing.

\section{Recommendations}

Based on the findings of the study and other established facts, the following recommendations were made:

- There is a need for early intervention that targets university students on Khat chewing. Universities should inform their students, about the problems associated with Khat chewing. The university should prepare open forums, regular workshops and conferences to create understanding on effects of Khat chewing in collaboration with psychiatrists and psychologists. Universities should teach and counsel their students on ways of coping with the problems rather than starting to chew Khat. In addition to this, there should be enough recreational areas for students in the university.

- Parental Khat chewing should also be addressed in adolescent Khat chewing prevention programs. Parents should be role models to their children by not chewing. They should not expose their children to Khat chewing. The students should also be informed about proper management of money.

- The ministry of education, high schools and university administrators should intervene accordingly by incorporating intervention programs, focusing on reducing Khat chewing prevalence. Policy makers should control the production and distribution of Khat.

- Through continuous awareness creation on the impact of Khat chewing, the students who were not chewers were not to be enforced by their Khat chewing friends, and the chewers should not enforce non-chewer friends to chew Khat.

\section{Acknowledgements}

First and for most, I give honour to GOD, the omnipotent for every protection to me and my families. I would like to extend my deepest gratitude to my advisor, Dr. Alemayehu Mekonnen, for his friendly approach, assistance, concern, and support in each and every step of my thesis. My deepest gratitude also goes to all who assisted me in searching and providing me relevant literature references in particular School of Public Health librarians. I am also grateful to Addis Ababa University for coordinating as well as granting a fund to the thesis.

I would like to extend my deepest gratitude to the Adama Town Administrative Bureau and Revenue Bureau for their cooperation in giving me the background of Adama Town and the habit of Khat chewing in the Town. My special thanks also go to the Vice Dean, all the school heads, instructors and lecturers, administration bodies and registrar office of the Adama University, students who participated in the study, and data collectors.

\section{References}

[1] Gorfu, M. (2006) The Prevalence of Khat-Induced Psychotic Reactions among College Students: Case in Jimma University College of Agriculture. Ethiopia Journal of Education and Science, 2, 63-84.

[2] National Drug Intelligence Center (2003) Khat (Catha edulis). Intelligence Bulletin. http://www.justice.gov/ndic/pubs3/3920/index.htm webcite

[3] Beckerleg, S. (2008) Khat Special Edition Introduction. Substance Use and Misuse, 43, 749-761. http://dx.doi.org/10.1080/10826080701739057

[4] Getahun, W., Gedif, T. and Tesfaye, F. (2010) Regular Khat (Catha edulis) Chewing Is Associated with Elevated Diastolic Blood Pressure among Adults in Butajira, Ethiopia: A Comparative Study. BMC Public Health, 10, 390. http://dx.doi.org/10.1186/1471-2458-10-390

[5] Kebede, Y., Abula, T., Ayele, B., Feleke, A., Degu, G., Kifle, A., et al. (2005) Substance Abuse Module. University of Gondar, Gondar.

[6] Fantahun, M. and Chala, F. (1996) Sexual Behaviour, and Knowledge and Attitude towards HIV/AIDS among Out of School Youth in Bahir Dar Town. Ethiopian Medical Journal, 34, 233-242. 
[7] Abate, S. (2001) Determinants of High Risk Sexual Behavior for HIV/AIDS among Out of School Youth in Addis Ababa. MPH Thesis, Addis Ababa University, Addis Ababa.

[8] Kassaye, M., Hassen, S., Ghimja, F. and Teshome, T. (1999) Drug Use among High School Students in Addis Ababa and Butajira. Ethiopian Journal of Health Development, 13, 101-106.

[9] Belew, M., Kebede, D., Kassaye, M. and Enquoselassie, F. (2000) The Magnitude of Khat Use and Its Association with Health, Nutrition and Socio-Economic Status. Ethiopian Medical Journal, 38, 11-26.

[10] Alem, A., Kebede, D. and Kullgren, G. (1999) The Epidemiology of Problem Drinking in Butajira, Ethiopia. Acta Psychiatrica Scandinavica, 397, 77-83. http://dx.doi.org/10.1111/j.1600-0447.1999.tb10698.x

[11] Kebede, D., Alem, A., Mitike, G., Enquselassie, F., Berhane, F., Abebe, Y., et al. (2005) Khat and Alcohol Use and Risky Sex Behaviour among In-School and Out-of-School Youth in Ethiopia. BMC Public Health, 5, 109. http://dx.doi.org/10.1186/1471-2458-5-109

[12] Weir, S. (1985) Qat in Yemen: Consumption and Social Changes. British Museum Press, London.

[13] Hassan, N., Gunaid, A. and Murray-Lyon, I. (2007) Khat (Catha edulis): Health Aspects of Khat Chewing. Eastern Mediterranean Health Journal, 13, 706-718.

[14] Stevenson, M., Fitzgerald, J. and Banwell, C. (1996) Chewing as a Social Act: Cultural Displacement and Khat Consumption in the East African Communities of Melbourne. Drug and Alcohol Review, 15, 73-82. http://dx.doi.org/10.1080/09595239600185691

[15] World Health Organization (1998) Youth and HIV/AIDS: Forces for Change (Report). Joint United Nations Programme on HIV/AIDS, Geneva, 22-40.

[16] Central Statistical Agency (2014) Ethiopian Demographic and Health Survey of 2011. Addis Ababa.

[17] Kebede, Y. (2002) Cigarette Smoking and Khat Chewing among College Students in North West Ethiopia, 2001. Ethiopian Journal of Health Development, 16, 9-17. http://dx.doi.org/10.4314/ejhd.v16i1.9818

[18] Gelaw, Y. and Haile-Amlak, A. (2004) Khat Chewing and Its Socio-Demographic Correlates among the Staff of Jimma University. Ethiopian Journal of Health Development, 18, 179-184.

[19] Kebede, Y. (2002) Cigarette Smoking and Khat Chewing among University Instructors in Ethiopia. East African Medical Journal, 79, 274-278. http://dx.doi.org/10.4314/eamj.v79i5.8869

[20] Deressa, W. and Azazh, A. (2011) Substance Use and Its Predictors among Undergraduate Medical Students of Addis Ababa University in Ethiopia. BMC Public Health, 11, 660. http://dx.doi.org/10.1186/1471-2458-11-660

[21] Redda, A.A., Moges, A., Biadgilign, S. and Wondmagegn, B.Y. (2012) Prevalence and Determinants of Khat Chewing among High School Students in Eastern Ethiopia: A Cross-Sectional Study. PloS ONE, 7, e33946. http://dx.doi.org/10.1371/journal.pone.0033946

[22] Meressa, K., Mossie, A. and Gelaw, Y. (2009) Effect of Substance Use on Academic Achievement of Health Officer and Medical Students of Jimma University, South West Ethiopia. Ethiopian Journal of Health Sciences, 19, 155-163.

[23] Odenwald, M., Neuner, F., Schauer, M., Elbert, T., Catani, C., Lingenfelder, B., et al. (2005) Khat Use as Risk Factor for Psychotic Disorders: A Cross-Sectional and Case-Control Study in Somalia. BMC Medicine, 3, 5-12. http://dx.doi.org/10.1186/1741-7015-3-5

[24] Alemu, H., Mariam, D.H., Belay, K.A. and Davey, G. (2007) Factors Predisposing Out-of-School Youths to HIV/AIDSRelated Risky Sexual Behaviour in Northwest Ethiopia. Journal of Health Population Nutrition, 25, 344-350.

[25] Damena, T., Mossie, A. and Tesfaye, M. (2011) Khat Chewing and Mental Distress: A Community Based Study, in Jimma City, Southern Ethiopia. Ethiopian Journal of Health Sciences, 21, 37-45. http://dx.doi.org/10.4314/ejhs.v21i1.69042

[26] Tesfaye, F., Byass, P., Berhane, Y., Bonita, R. and Wall, S. (2008) Association of Smoking and Khat Use with High BP among Adults in Addis Ababa, Ethiopia, 2006. Centre for Disease Prevention and Control, 5, A89.

[27] Mossie, A. (2002) The Prevalence and Socio-Demographic Characteristics of Khat Chewing in Jimma Town, South Western Ethiopia. Ethiopian Journal of Health Science, 12, 69-80.

[28] Negussie, B. (2012) Substance Use among High School Students in Dire Dawa, Ethiopia. Harar Bulletin of Health Sciences, 4, 38-52.

[29] Milat, W.A., Salih, M.A., Bani, I.A. and Ageely, H.M. (2005) Jazan Need Assessment Health Survey. Final Report for Project No (636/425) 2005, Faculty of Medicine, Jazan King Abdulaziz University, Jazan.

[30] Elisanosi, R., Bani, I., Ageely, H., Milaat, W., Eli-Najjar, M., Makeen, A., et al. (2011) Socio-Medical Problems of the Habituation of Khat Chewing in Jazan Region in Southern Saud Arabia. European Journal of Scientific Research, 63, 122-133.

[31] Adugna, F., Jira, C. and Molla, T. (1994) Khat Chewing among Agaro Secondary School Students, Agaro, South- 
Western Ethiopia. Ethiopian Medical Journal, 32, 161-166.

[32] Zein, A. (1988) Polydrug Abuse among Ethiopian University Students with Particular Reference to Khat (Catha edulis). Journal of Tropical Medicine Hygiene, 91, 71-75.

[33] Abebe, D., Debella, A., Dejene, A., Degefa, A., Abebe, A., Urga, K., et al. (2005) Khat Chewing Habit as a Possible Risk Behaviour for HIV Infection: A Case-Control Study. Ethiopian Journal of Health Development, 19, 174-181.

[34] Seme, A., Mariam, D.H. and Worku, A. (2005) The Association between Substance Abuse and HIV Infection among People Visiting HIV Counselling and Testing Centres in Addis Ababa, Ethiopia. Ethiopian Journal of Health Development, 19, 116-125. http://dx.doi.org/10.4314/ejhd.v19i2.9980

[35] Oromia Regional State Adama City Administrative Revenue Enhancement Plan, March 2010, Adama. 